\title{
ЛОГІКА ПРИЙНЯТТЯ РІШЕНЬ В ОЦІНЮВАННІ ЕФЕКТИВНОСТІ МЕДИЧНОГО СТРАХУВАННЯ - ПРИНЦИПИ ПОРІВНЯЛЬНОГО АНАЛІЗУ
}

\author{
С. О. Джундубаєва
}

\author{
Страхова медична компанія АТ КК ЗіМС «lнтертіч», Казахстан
}

\begin{abstract}
Розглянуто питання вдосконалення медичної страхової діяльності шляхом використання технології мониторингового аналізу показників діяльності страхової компанії. Використовуються коефіцієнти погодженості трендів, коефіцієнти очікування результатів тощо. Основними показниками моніторингу слугували інтегральні характеристики, на кшталт дотримання протоколів діагностики та лікування. Особливу увагу звернено на оцінювання задоволеності пацієнтів.
\end{abstract}

Ключові слова: ефективність медичного страхування, кількісна оцінка трендів, якість надання медичної допомоги, задоволеність пацієнтів, лікарські помилки, прийняття рішень, інформаційні взаємозв'язки.

\section{ЛОГИКА ПРИНЯТИЯ РЕШЕНИЙ ПРИ ОЦЕНКЕ ЭФФЕКТИВНОСТИ МЕДИЦИНСКОГО СТРАХОВАНИЯ - ПРИНЦИПЫ СОПОСТАВИТЕЛЬНОГО} АНАЛИЗА

С. О. Джундубаєва

Страховая медицинская компания АО КК ЗиМС «Интертич», Казахстан

\begin{abstract}
Рассмотрены вопросы совершенствования медицинской страховой деятельности путем использования технологий мониторингового анализа показателей деятельности страховой компании. Использовались коэффициенты согласованности трендов, коэффициенты ожидания результатов и т.д. Основными показателями мониторинга служили интегральные характеристики, например, соблюдение протоколов диагностики и лечения. Особое внимание обращено на показатели неудовлетворенности пациентов. Исследовано качество оказания медицинской помощи у 5000 пациентов со 135 предприятий. Рассмотрены причины и следствия случаев ненадлежащего оказания медицинской помощи в результате несоблюдения ее объемов или качества.

Проанализирован ы перспективы использования информационно - математической стратегии для оценки трендов несоответствия помощи существующим стандартам и протоколам. Отмечен удельный вес диагностических и лечебных мероприятий, проведенных не в полном объеме, по причинам, зависящим от врача и приведших к ухудшению состояния пациента и удлинению сроков лечения.
\end{abstract}

Ключєвьіє слова: эффективность медицинского страхования, количественная оценка трендов, качество оказания медицинской помощи, удовлетворенность пациентов, принятие решений, информационные взаимосвязи.

\section{LOGIC OF DECISION-MAKING IN ASSESSING THE EFFECTIVENESS OF HEALTH INSURANCE - THE PRINCIPLES OF COMPARATIVE ANALYSIS}

\section{Insurance Medical Company «Interteach», Kazakhstan}

\begin{abstract}
The problems of improving the health insurance business through the use of technology monitoring performance analysis of the insurance company are discussed. It was used the coefficients of consistency trend; the waiting for the results coefficients, etc. The main indicators for monitoring were integral characteristics, such as compliance with diagnostic and treatment protocols. Particular attention is paid to the performance of dissatisfaction with patients. There was investigated the quality of medical care in 5000 patients with 135 enterprises. It was discussed the causes and consequences of cases of improper medical care as a result of non-compliance with its quantity or quality and the prospects of the use of information - mathematical strategies to assess trends in non-compliance by existing standards and protocols. It was marked proportion of diagnostic and therapeutic measures carried out not in full due to reasons beyond the control of the doctor and led to a deterioration of the patient's condition and lengthening the period of treatment.
\end{abstract}

Key words: health insurance efficiency, the quantitative evaluation of trends, quality of care, patient satisfaction, decisionmaking, information relationship.

(C) С. О. Джундубаєва 
Вступление. На современном этапе развития общества представляется маловероятным охарактеризовать эффективность какой-либо системы медицинского страхования единственным формализованным интегрированным показателем. В этом смысле эффективность здравоохранения, равно и эффективность обязательного медицинского страхования, как систем по удовлетворению спроса на медицинские услуги, не может быть определена однозначно.

Подтверждением многоуровневого подхода к оценкам эффективности отдельных составляющих системы медицинского страхования является широкий спектр предлагаемых методик и показателей, используемых и рекомендуемых отдельными авторами для оценки деятельности системы и ее составляющих. Среди предложенных характеристик можно назвать комплексы натуральных, стоимостных и относительных показателей, характеризующих результаты как медицинской профессиональной работы, так и хозяйственной деятельности в здравоохранении [3]. Разумеется, можно с определенным успехом применить традиционные методы: занятость койко-мест для стационаров, а для поликлиник - количество посещений пациентов (клиентов) в единицу времени [1]. Используется также и сопоставительный анализ путем сравнения показателей лечения застрахованных больных с таковыми у незастрахованных больных.

Особенно часто встречается ошибка, когда при заполнении таблицы сопоставительного анализа в группу способа «последовательность действий» формально записывают последовательность всех действий, составляющих способ, невзирая на существенность этой последовательности.

В принципе, характеристики организаций можно получить, анализируя различные показатели работы фирмы и связи между ними. Например, для описания деятельности страховой компании используется порядка 30 различных показателей. Комплексно проанализировать столь большое число параметров практически невозможно. Поэтому часто выбираются несколько наиболее важных, с точки зрения экспертов, параметров, которые и отображают сопоставительный процесс. Однако при таком подходе сильно огрубляется модель, из-за чего возможно получение некорректных результатов.

Более общий подход заключается в использовании не каких-либо двух, достаточно произвольно выбранных параметров, а использование двух линей ных комбинаций всех параметров. Такие методы позволяют провести линейное приближение различных параметров. Но и линейная обработка не всегда способна выделить ведущие параметры, описывающие состояние фирм с приемлемой точностью.

Предполагается, что наиболее удобным статистическим подходом является кластерный анализ (например по методу нейронных сетей). Существует сеть, которая как раз позволяет отобразить искомый набор параметров, число которых может быть очень большим, в виде двух координат на плоскости.

Определенные методики статистической оценки деятельности страховых медицинских организаций позволяют получать усредненные данные по ряду компаний, указывают место каждой такой компании в ряду прочих и с определенной долей достоверности дают интегрированную картину дел в области страхования населения.

Цель работы: исследовать перспективы использования информационно-математической стратегии для оценки трендов несоответствия медицинской помощи населению существующим стандартам и протоколам.

Материал и методы исследования. Изучались результаты анализа 5000 страховых случаев в 135 лечебно-профилактических учреждениях Республики Казахстан (РК). Все они входили в страховой кластер АО КК ЗиМС «Интертич». Медицинская помощь оказывалась лечебными учреждениями РК в 2013 году. Параллельно с данными об эффективности медицинской помощи использовались также и социологические методы. Они состоят в изучении мнения пациентов о различных аспектах качества медицинской помощи путем анкетирования по специально разработанной карте.

Результаты и их обсуждение. В самом широком понимании - эффективность страховых компаний связана с удовлетворением спроса населения. Подобный подход помогает выделить и впоследствии классифицировать основные направления, по которым представляется возможным, в определенной степени, решить проблему оценки эффективности системы страхования и вести целенаправленные исследования в этом направлении.

В построении модели объективных оценок оптимальности и эффективности системы обязательного медицинского страхования могут быть использованы параметры традиционных существующих критериев деятельности лечебных учреждений, разработаны новые показатели и спрогнозированы перспективные. 
Эффективность конкретной модели территориального уровня системы медицинского страхования может оцениваться в пределах комплекса показателей. К основным можно отнести: заранее обоснованные показатели здоровья населения; адекватность производственной базы медицинских услуг соответствующему объему спроса медицинских процедур; экономические критерии устойчивости и оптимального функционирования системы страхования, как производства; критерии оценки эффективности по степени выполнения стандартов, применяемые в системе здравоохранения; критерии оценки эффективности по результатам ведомственной и вневедомственной экспертизы качества медицинской помощи; критерии оценки эффективности по данным социального мониторинга.

Понятно, что каждый из перечисленных показателей требует формализации и стандартизации оценки. Выбор определенного и достаточного набора показателей из множества параметрических характеристик, объективно описывающих степень оптимизации системы (в частности ее эффективности) на том или ином уровнях, позволяет приблизиться к объективной оценке функционирования системы страхования на конкретной территории и в конкретном временном интервале.

Из трех видов эффективности страхования в здравоохранении (социальной, медицинской и экономической) наиболее реально определение медицинской эффективности. Она включает оценку результативности различных способов диагностики, лечебных процедур, в том числе лекарственных средств. Исключительный интерес может представить и эффективность различных мер профилактики, в том числе специфической (прививок), которую можно выразить через различные показатели качества и эффективности деятельности медицинских учреждений (сокращение средних сроков диагностики, средней длительности заболевания, пребывания больного в стационаре) и др.

Что касается экономической эффективности, то ее вычисление не приняло государственных масштабов. По крайней мере, стандартов применения показателей данного вида эффективности пока не существует.

В практической плоскости логика принятия решений в управлении страховой компании базируется не на использовании многочисленных показателей, а на применении наиболее иллюстративной их части, получивших название индикаторов. Последние особенно эффективны при их использовании в процессе $м о$ - ниторинга динамики объёмов потребления медицинской помощи и оценки деятельности медицинского учреждения. Полученные в результате данные способствуют улучшению экономической и социальной эффективности медицинского учреждения, проводимой в нем политики улучшения качества медицинской помощи, путём чёткого выявления как тех компонентов, что работают хорошо, так и тех, что работают плохо. На основании полученных оценок отклонения достигнутых показателей от порогового значения определяется общий коэффициент достижения результатов (индекс результативности). Последний может привести к пересмотру отдельных тактических мероприятий, приостановке тех действий, которые кажутся неэффективными, и разработке новых подходов к преодолению проблем и устранению слабых мест.

Подчеркнем также, что внутренние индикаторы оценки качества медицинской помощи узких специалистов не оказывают влияния на интегральное качество медицинской помощи, а являются характеристикой степени воздействия влияющих факторов и управляющих мероприятий. Экономическая эффективность использования ресурсов выражается в соотношении достигнутого социально значимого результата и потраченных при этом ресурсов страховой компании. Эффективное расходование средств заключается в достижении удовлетворенности клиента желаемым результатом при максимальной экономии финансовых ресурсов.

Таким образом, правильный выбор показателей позволяет не только проводить комплексный анализ системы, но и информационно и экономически обеспечить выбор управляющих воздействий.

Нами изучена динамика результативности деятельности медицинского учреждения за период 20122014 гг. (табл. 1). Данные результаты были достигнуты путем проведения предварительной экспертизы всех медицинских подразделений и принятия политики обеспечения качества медицинской помощи (КМП).

Как видно из таблицы 1, наблюдается заметное улучшение КМП. Диагностические мероприятия, проведенные не в полном объеме по причинам, зависящим от врача и приведшие к неправильной диагностике, уменьшились почти в четыре раза с 4,0\% до $1,2 \%(\mathrm{p}<0,05)$. Столь же заметны улучшения в значении индикатора «Лечебные мероприятия, проведенные не в полном объеме по причинам, зависящим от врача и приведшие к ухудшению состояния пациента и удлинению сроков лечения». 
Таблица 1. Индикаторы деятельности медицинских учреждений, работающих в кластере страховой медицины АО КК ЗиМС «Интертич»

\begin{tabular}{|c|c|c|c|c|c|c|c|}
\hline $\begin{array}{l}\text { № } \\
\Pi / \Pi\end{array}$ & $\begin{array}{c}\text { Наименование } \\
\text { индикаторов }\end{array}$ & $\begin{array}{c}\text { Периодичность } \\
\text { информации }\end{array}$ & $\begin{array}{c}\text { Источник } \\
\text { информации }\end{array}$ & Ориентиры & 2012 г. & 2013 г. & $\begin{array}{c}\text { I } \\
\text { полугодие } \\
2014 \text { г. } \\
\end{array}$ \\
\hline 1. & $\begin{array}{l}\text { Диагностические } \\
\text { мероприятия, } \\
\text { проведенные не в } \\
\text { полном объеме по } \\
\text { причинам, зависящим } \\
\text { от врача и приведшие к } \\
\text { неправильной } \\
\text { диагностике }\end{array}$ & 1 раз в квартал & $\begin{array}{l}\text { Амбулаторная } \\
\text { карта } \\
\Phi 025 / \mathrm{y}\end{array}$ & $0 \%$ & $4 \%$ & $2 \%$ & $1,2 \%$ \\
\hline 2. & $\begin{array}{l}\text { Лечебные } \\
\text { мероприятия, } \\
\text { проведенные не в } \\
\text { полном объеме по } \\
\text { причинам, зависящим } \\
\text { от врача и приведшие к } \\
\text { ухудшению состояния } \\
\text { пациента и удлинению } \\
\text { сроков лечения }\end{array}$ & 1 раз в квартал & $\begin{array}{l}\text { Амбулаторная } \\
\text { карта } \\
\Phi 025 / y\end{array}$ & $0 \%$ & $0,8 \%$ & $0,4 \%$ & $0,1 \%$ \\
\hline 3. & $\begin{array}{l}\text { Наличие случаев } \\
\text { полипрагмазии, } \\
\text { приведших к } \\
\text { удорожанию } \\
\text { стоимости лечения } \\
\text { среди застрахованных }\end{array}$ & 1 раз в квартал & $\begin{array}{l}\text { Амбулаторная } \\
\text { карта } \\
\Phi 025 / y\end{array}$ & $0 \%$ & $0,4 \%$ & $0,4 \%$ & $0,2 \%$ \\
\hline 4. & $\begin{array}{l}\text { Госпитализация без } \\
\text { медицинских } \\
\text { показаний }\end{array}$ & 1 раз в месяц & $\begin{array}{l}\text { Журнал } \\
\text { госпитализации } \\
\text { Ф001-6/y }\end{array}$ & $\begin{array}{l}\text { Показатель } \\
\text { должен } \\
\text { стремиться } \\
\text { к нулю }\end{array}$ & 0,5 & 0,4 & 0 \\
\hline 5. & $\begin{array}{l}\text { Обоснованность } \\
\text { выдачи врачами } \\
\text { подразделений листов } \\
\text { и справок временной } \\
\text { нетрудоспособности }\end{array}$ & 1 раз в квартал & $\begin{array}{l}\text { Амбулаторные } \\
\text { карты } \\
\text { пациентов, } \\
\text { журнал ВКК }\end{array}$ & $\begin{array}{l}\text { Показатель } \\
\text { должен } \\
\text { стремиться } \\
\text { к нулю }\end{array}$ & 0,1 & 0,1 & 0 \\
\hline 6. & $\begin{array}{l}\text { Случаи развития } \\
\text { осложнений при } \\
\text { проведении } \\
\text { манипуляций врачом, } \\
\text { повлекшие за собой } \\
\text { ухудшение состояния } \\
\text { пациента }\end{array}$ & 1 раз в квартал & $\begin{array}{l}\text { Амбулаторная } \\
\text { карта } \\
\Phi 025 / y, \\
\text { отчетные } \\
\text { данные }\end{array}$ & $0 \%$ & 0,01 & 0 & 0 \\
\hline 7. & $\begin{array}{l}\text { Общее количество } \\
\text { обоснованных жалоб за } \\
\text { отчетный период по } \\
\text { сравнению с } \\
\text { предыдущим периодом }\end{array}$ & 1 раз в квартал & $\begin{array}{l}\text { Журнал } \\
\text { регистрации } \\
\text { обращений, } \\
\text { письменные } \\
\text { жалобы }\end{array}$ & $\begin{array}{l}\text { Значение } \\
\text { должно } \\
\text { снижаться на } \\
10 \text { \% по } \\
\text { сравнению с } \\
\text { предыдущим } \\
\text { периодом }\end{array}$ & $\begin{array}{l}\text { До } 6 \\
\text { жалоб }\end{array}$ & $\begin{array}{l}\text { В сред- } \\
\text { нем } 5 \\
\text { жалоб } \\
\text { в } \\
\text { квартал }\end{array}$ & $\begin{array}{l}\text { В среднем } \\
2 \text { жалобы в } \\
\text { квартал }\end{array}$ \\
\hline
\end{tabular}

Они также статистически достоверно отражают уменьшение показателя с 0,8 \% до 0,1 \%. В то же время практически не изменились индикаторы «Обоснованность выдачи врачами подразделений листов и справок временной нетрудоспособности», «Случаи разви- тия осложнений при проведении манипуляций врачом, повлекшие за собой ухудшение состояния пациента».

По-видимому, истинное положение дел в таких индикаторах скорее связано с проблемами выявления подобных случаев и их регистрацией. 
Близкие результаты получены и в исследовании деятельности амбулаторно-поликлинического звена ме- дицинских учреждений, работающих в кластере страховой медицины АО КК ЗиМС «Интертич» (табл. 2).

Таблица 2. Индикаторы деятельности амбулаторно-поликлинического звена страхового кластера АО КК ЗиМС «Интертич»

\begin{tabular}{|c|c|c|c|c|c|c|c|c|}
\hline $\begin{array}{l}\text { № } \\
\Pi / \Pi\end{array}$ & Наименование показателей & $\begin{array}{c}\text { Источник } \\
\text { информации }\end{array}$ & $\begin{array}{c}\text { Единица } \\
\text { измерения }\end{array}$ & Ориентиры & $\begin{array}{l}\text { Оценка } \\
\text { в баллах }\end{array}$ & 2012 & 2013 & $\begin{array}{c}2014 \\
\text { I полу- } \\
\text { годие }\end{array}$ \\
\hline \multirow[t]{2}{*}{1.} & \multirow[t]{2}{*}{$\begin{array}{l}\text { Соблюдение протоколов } \\
\text { диагностики и лечения }\end{array}$} & \multirow{2}{*}{$\begin{array}{l}\text { Экспертиза не } \\
\text { менее } 25 \\
\text { медицинских } \\
\text { карт }\end{array}$} & \multirow{2}{*}{$\begin{array}{l}\text { Количество } \\
\text { выявленных } \\
\text { случаев } \\
\text { нарушений }\end{array}$} & \multirow[t]{2}{*}{ Отсутствие } & \multirow[t]{2}{*}{5} & \multicolumn{3}{|c|}{$\begin{array}{c}\text { Количество случаев } \\
\text { нарушений }\end{array}$} \\
\hline & & & & & & 6,3 & 4,2 & 1,1 \\
\hline 2. & $\begin{array}{l}\text { Наличие обоснованных } \\
\text { жалоб со стороны пациента } \\
\text { и его родственников на } \\
\text { качество оказанной } \\
\text { медицинской помощи }\end{array}$ & $\begin{array}{l}\text { Журнал учета } \\
\text { обращений } \\
\text { граждан }\end{array}$ & $\begin{array}{l}\text { Абсолютное } \\
\text { число жалоб }\end{array}$ & $\begin{array}{l}\text { Отсутствие } \\
\text { жалоб }\end{array}$ & 5 & 4,1 & 4,6 & 4,7 \\
\hline 4. & $\begin{array}{l}\text { Удовлетвор енность } \\
\text { застрахованных пациентов } \\
\text { лечебно-диагностическим } \\
\text { процессом }\end{array}$ & Анкетирование & $\begin{array}{l}\text { Не менее } 25 \\
\text { анкет на леча- } \\
\text { щего врача }\end{array}$ & & 5 & 3,1 & 4,5 & 4,7 \\
\hline 5. & $\begin{array}{l}\text { Число расхождений } \\
\text { диагнозов при направлении } \\
\text { в стационар и клиничес- } \\
\text { кого диагноза стационара }\end{array}$ & $\begin{array}{l}\text { Выписка из } \\
\text { стационара }\end{array}$ & $\begin{array}{l}\text { Количество } \\
\text { случаев }\end{array}$ & Отсутствие & 5 & 4,7 & 4,7 & 5 \\
\hline
\end{tabular}

Если рассматривать индикатор «Соблюдение протоколов диагностики и лечения», возможно заметить выраженную тенденцию к улучшению качества медицинской помощи. Количество случаев нарушений протоколов уменьшилось с 6,3\% до $1,1 \%$ (p<0,05).

Если же анализировать динамику индикаторов «Наличие обоснованных жалоб со стороны пациента и его родственников на качество оказанной медицинской помощи» или же «Число расхождения диагнозов при направлении в стационар и клинического диагноза стационара» то статистически достоверных различий в процессе наблюдений отметить нереально.

Соответственно можно констатировать, что при необходимости оценить степень достижения поставленных целей, путем сопоставления достигнутых и плановых показателей мы можем, при желании, засвидетельствовать значительный прогресс. Однако,

\section{Литература}

1. Быкова Ж. Е. Использование методики бальной оценки медицинских услуг в качестве стабилизирующего фактора расходов на здравоохранение / Ж. Е. Быкова // Экономика здравоохранения. - 1998. - №2 10, 11. - С. 12-15.

2. Жданов А. М. Анализ экономической эффективности "Автоматизированной системы учета оказания медицинских услуг по программе ОМС в медицинских учреждени- объективный анализ для обоснования логики принятия решений при оценке эффективности медицинского страхования не будет возможным без утверждения стандартов оценки результатов оказания медицинской помощи населению.

Выводы. 1. Динамика показателей эффективности в страховой медицине не может быстро отразить глобальный характер изменений. Определяющим в принятии решений о дальнейшей деятельности страховой компании являются лишь тренды, причем принципиальным является результат в многомерном пространстве показателей.

2. Необходимыми являются разработка и утверждение количественных стандартов оценки оказания медицинской помощи населению.

2. Наиболее эксквизитным индикатором качества страховой деятельности является соблюдение стандартов оказания медицинской помощи.

ях г. Москвы" / А. М. Жданов // Экономика здравоохранения. - 1998. - № 2 . - С. 18-21.

3. Лебедев А. А. ОМС сквозь призму статистики / А. А. Лебедев, И. В. Лебедева // Экономика здравоохранения. 1997. - № 8 - 9 . - С. 44-50.

4. Лисицын Ю. П. Концепция "человеческого капитала": медико-экономический аспект / Ю.П. Лисицын // Экономика здравоохранения. - 1998. - №2 . - С. 5-9. 